\title{
Sampling and analysis of coarsely shredded mixed commercial waste. Part Il: particle size-dependent element determination
}

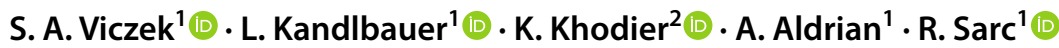

Received: 4 January 2021 / Revised: 23 June 2021 / Accepted: 19 July 2021 / Published online: 21 August 2021

(c) The Author(s) 2021

\begin{abstract}
In contemporary waste management, sampling of waste is essential whenever a specific parameter needs to be determined. Although sensor-based continuous analysis methods are being developed and enhanced, many parameters still require conventional analytics. Therefore, sampling procedures that provide representative samples of waste streams and enable sufficiently accurate analysis results are crucial. While Part I estimated the relative sampling variabilities for material classes in a replication experiment, Part II focuses on relative sampling variabilities for 30 chemical elements and the lower heating value of the same samples, i.e., 10 composite samples screened to yield 9 particle size classes $(<5 \mathrm{~mm}-400 \mathrm{~mm})$. Variabilities $<20 \%$ were achieved for $39 \%$ of element-particle size class combinations but ranged up to $203.5 \%$. When calculated for the original composite samples, variabilities $<20 \%$ were found for $57 \%$ of the analysis parameters. High variabilities were observed for elements that are expectedly subject to high constitutional heterogeneity. Besides depending on the element, relative sampling variabilities were found to depend on particle size and the mass of the particle size fraction in the sample. Furthermore, Part I and Part II results were combined, and the correlations between material composition and element concentrations in the particle size classes were interpreted and discussed. For interpretation purposes, log-ratios were calculated from the material compositions. They were used to build a regression model predicting element concentration based on material composition only. In most cases, a prediction accuracy of $\pm 20 \%$ of the expected value was reached, implying that a mathematical relationship exists.
\end{abstract}

Keywords Contaminants $\cdot$ Element-material correlation $\cdot$ Heavy metals $\cdot$ Replication experiment $\cdot$ Relative sampling variability $\cdot$ Solid recovered fuel

\section{Introduction}

The assessment of the quality and the categorization of waste are usually based on various analytical results. Chemical parameters that are particularly important for quality assessment are the concentrations of various heavy metals,

Editorial responsibility: Binbin Huang.

R. Sarc

renato.sarc@unileoben.ac.at

1 Chair of Waste Processing Technology and Waste Management, Department of Environmental and Energy Process Engineering, Montanuniversitaet Leoben, Franz-Josef-Strasse 18, 8700 Leoben, Austria

2 Chair of Process Technology and Industrial Environmental Protection, Department of Environmental and Energy Process Engineering, Montanuniversitaet Leoben, Franz-Josef-Strasse 18, 8700 Leoben, Austria metalloids, and other inorganic contaminants (cf. EC 2008a Annex III; EC 2008b Annex VI). These elements frequently occur in mixed commercial waste (MCW) and mixed municipal solid waste (MMSW) because they are present in various consumer goods and materials (e.g., Turner 2019; Turner and Filella 2017; Viczek et al. 2020). Their concentrations play a decisive role in various waste processing options (see "Importance of heavy metal and metalloid concentrations" section). However, because usually "analytical results are estimates of unknown quantities" (Gy 1995), they are subject to uncertainties, many of which are related to heterogeneity. Since mixed solid wastes are usually highly heterogeneous and tend to segregate (Pomberger et al. 2015), sampling of waste can be challenging.

Figure 1 shows an example of uncertainties related to the different steps of the analytical procedure at the example of lead (Pomberger et al. 2015). Flamme and Gallenkemper (2001) state even higher analysis uncertainties: the 
Fig. 1 Uncertainties related to the single steps of the analytical procedure at the example of lead in mixed solid waste. Adapted from Pomberger et al. (2015)

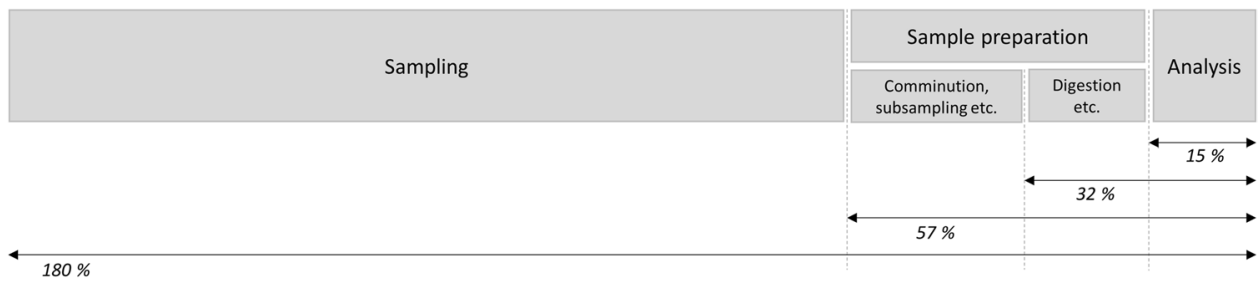

uncertainty related to sampling can range up to $1000 \%$ if the sample is taken from a stationary waste pile, and uncertainties of 100-300\% can be expected for sample preparation. While the propagation of uncertainties in all process steps leads to a general variance of the analysis results (Krämer et al. 2016), the contribution of primary sampling to the measurement uncertainty and variability is often dominant (Ellison and Williams 2012; Esbensen and Julius 2009; Ramsey et al. 2019). For this reason, reliable and representative sampling is crucial. Although various sampling standards exist, the sampling quality can still be influenced by on-site circumstances (e.g., the possibility to take the sample from the falling stream or a stationary pile).

Because of the effort, errors, and uncertainties related to the sampling of heterogeneous waste materials, researchers are also looking for continuous, real-time methods to determine specific parameters in waste. The investigated methods are usually sensor-based and aiming at ideally generating results without sampling and sample preparation procedures. Real-time methods for the characterization of solid waste are reviewed in detail by Vrancken et al. (2017) and include laser-induced breakdown spectroscopy (LIBS), X-ray, or near-infrared (NIR) technology. The most established of these techniques in the waste sector is NIR, which has been used for sorting purposes since the 1990s (Krämer et al. 2016). NIR technology was found to deliver good real-time results for solid recovered fuels for the higher heating value (HHV), lower heating value (LHV), water, ash, and $\mathrm{Cl}$ content. However, results achieved for $\mathrm{Sb}, \mathrm{Cd}, \mathrm{Pb}$, and $\mathrm{Cr}$ are currently considered insufficient for quantitative analyses, and realtime measurements should be limited to qualitative analyses (Krämer et al. 2016; Krämer 2017).

However, as long as real-time technologies are not applicable for all relevant parameters, need further enhancement or comparison with results from conventional analyses, and are not state of the art in waste treatment plants, sampling remains crucial to determine the properties of waste streams and the related uncertainties need to be known and handled correctly.

\section{Importance of heavy metal and metalloid concentrations}

Concentrations of heavy metals and metalloids are not only relevant in the consumer products sector but also in the postconsumer regime. In the latter, contaminant concentrations play a significant role in determining suitable waste treatment pathways. Generally, contaminant concentrations determine whether or not a waste is considered hazardous (EC 2008a, b), and in the case of non-hazardous waste, which is in the focus of this study, they can be a decisive factor for the selection or applicability of several waste treatment options:

When landfilled, leaching of certain elements from waste can pose a possible risk to the environment (Kjeldsen et al. 2002). When composted, compost quality and composition depend on the purity of the input waste (e.g., separately collected organic waste or the separated undersize fraction from mechanical biological treatment of MSW) (Andersen et al. 2010; Smith 2009), and heavy metal limits for compost standards exist in several countries (Amlinger et al. 2004). When incinerated, the amount of inorganic contaminants in the gaseous emissions which have to comply with limit values (e.g., Industrial Emissions Directive (EC 2010)) is strongly related to their amounts in the input waste (Astrup et al. 2011; Brunner and Rechberger 2015; Morf et al. 2000). Even when waste fractions are directed toward recycling, the concentration of inorganic contaminants can-among other factors-determine whether or not a particular material can indeed be recycled. Examples include plastics containing selected brominated flame retardants (Pivnenko et al. 2017; Slijkhuis 2018) or cadmium-containing PVC products (EC 2011). Another popular waste treatment option is to produce solid recovered fuels (SRF) for co-processing in cement kilns (Sarc et al. 2019). This option also requires the contaminants to be monitored because the contaminant concentrations in input fuel as well as the resulting output gaseous emissions and the product shall be kept at a low level (BMLFUW 2010). Depending on the country, compliance with limit values for certain chemical elements can either be requested directly by the cement manufacturers (Lorber et al. 2012), by quality marks (e.g., RAL GZ 724 quality mark for quality-assured SRF in Germany (Flamme and Geiping 2012)), or by the legislature (e.g., Austrian Waste Incineration Ordinance (WIO) (BMLFUW 2010)). Limit values for inorganic contaminants in SRF may be given in $\mathrm{mg} / \mathrm{MJ}$, taking the lower heating value (LHV) into account. This is the case for mercury in EN 15359 (ASI 2011d) and the eight heavy metals regulated by the Austrian WIO (BMLFUW 2010).

Due to the importance of contaminant concentrations for all these different waste treatment options, it is evident that knowledge on their distributions in waste and possibilities for 
their removal before the final waste treatment is of interest. To gain this information, sampling is unavoidable and required to enable a sufficiently accurate examination of the analytes. MCW typically contains large items, e.g., mattresses or furniture parts, which is why coarse shredding followed by one or more screening stages is typically the first step of MCW processing. While this step significantly facilitates sampling, as a vision of Khodier et al. (2020), varying shredder parameters could enable waste processors to steer the concentration of different material and contaminant streams into certain particle size fractions. To assess whether this is possible, prior knowledge about sampling variability and sampling errors is required.

\section{Theory of sampling}

In the theory of sampling (TOS), variability and sampling errors can be expressed by the global estimation error (GEE), which is the relative difference between the obtained analytical result and the actual, unknown value of the parameter. It is furthermore defined as the sum of the total sampling errors (TSE) and the total analytical errors (TAE) (Gy 2004). For significantly heterogeneous materials, the TAE plays a minor role as the sum of all sampling errors is usually significantly larger. The TSE originates from the sampling process or material heterogeneity and consists of correct sampling errors (CSE) and incorrect sampling errors (ISE) (Wagner and Esbensen 2012).

CSEs are caused by heterogeneity (Wagner and Esbensen 2012), two types of which are distinguished in TOS: constitutional heterogeneity $(\mathrm{CH})$ and distributional heterogeneity (DH) (Gy 2004). CH depends on the physical and/or chemical differences between individual fragments, i.e., the fact that single particles can contain small or only trace amounts of the analyte or can be almost entirely made of the analyte (e.g., iron traces in waste plastics vs. an iron particle in waste). With increasing compositional differences between the fractions, $\mathrm{CH}$ increases, thereby causing the fundamental sampling error. This correct sampling error can never be eliminated but can be decreased by comminution (Gy 1998; Wagner and Esbensen 2012). In contrast to $\mathrm{CH}$ being only dependent on material properties, DH reflects the irregular spatial distribution of the fragments in a lot (Esbensen and Wagner 2014; Wagner and Esbensen 2012). DH is caused by the tendency of fragments to locally segregate and group in space and time and is responsible for the second type of correct sampling error, the grouping, and segregation error. It can be counteracted by mixing and composite sampling, i.e., taking several small sample increments rather than fewer, larger sample increments (Wagner and Esbensen 2015).

While CSEs comprise material-specific errors that are always present in sampling situations, ISE concerns the sampling equipment and procedure (Wagner and Esbensen 2015).
ISE needs to be minimized or eliminated where possible as they are generating bias (Wagner and Esbensen 2012). ISE consists of the increment delimitation error (IDE), the increment extraction error (IEE), and the increment preparation error (IPE). While IDE and IEE concern errors occurring during the sampling process, IPE comprises all changes to the sample during or after sampling stages, including the loss of material (moisture, dust) and contamination (Wagner and Esbensen 2015).

One approach to estimate the GEE is to conduct a replication experiment, as described in DS 3077 (DS 2013). The replication experiment yields the relative sampling variability (RSV), also referred to as the relative coefficient of variation $\mathrm{CV}_{\text {rel }}$, a measure of the total sampling variance normalized by the arithmetic mean (Esbensen and Wagner 2014). RSV or $\mathrm{CV}_{\text {rel }}$, respectively, represent the GEE and are calculated according to Eq. (1), with $s$ being the standard deviation and $\bar{x}$ being the average of a set of analytical results (DS 2013; Wagner and Esbensen 2012):

$$
R S V[\%]=\left[\frac{s}{\bar{x}}\right] \times 100=C V_{\text {rel }}
$$

\section{Connection to part I and aim of the study}

Part I of this study presented by Khodier et al. (2020) introduced the theoretical background of the TOS in greater detail and reported the results of a replication experiment for MCW and the distribution of materials in terms of sorting fractions (e.g., metal, wood, paper, cardboard, plastics 2D, plastics 3D) among nine different particle size classes. The study reports RSVs of up to $231 \%$ and found that RSVs below $20 \%$, which is the general consensus acceptance threshold according to DS 3077, can only be achieved for less than half of the examined fractions. Furthermore, a decrease of the RSV with increasing mass shares of the fractions was observed.

The current paper, Part II, focuses on the chemical analysis of the different particle size fractions examined in Part I. While the RSVs reported by Khodier et al. (2020) mostly result from $\mathrm{DH}$, the chemical analyses presented in this paper are significantly influenced by $\mathrm{CH}$ as well. For example, different fragments that were merely classified as plastics for the material distribution can contain significantly different concentrations of heavy metals that will be reflected by the chemical analyses. Therefore, Part II determines the RSVs and thereby the GEEs for 30 elements and compares them with the results of Khodier et al. (2020). The current study focuses on sampling aspects; therefore, analysis results are only briefly summarized to facilitate interpretations of the results. The corresponding concentrations are presented and discussed in detail, focusing on SRF production in Viczek et al. (2021b). Furthermore, the results of Part I and Part II are combined by investigating correlations between material composition 


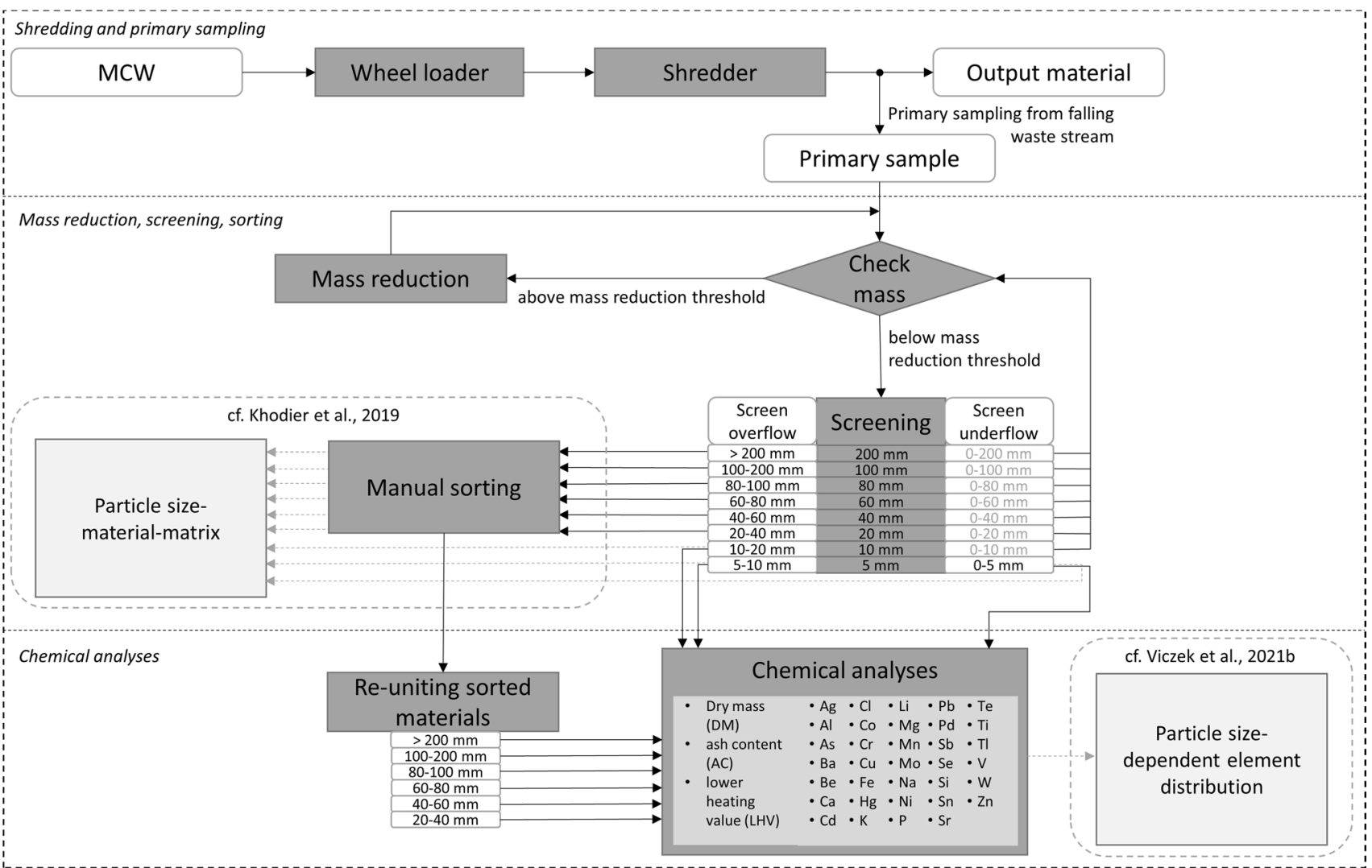

Fig. 2 Sampling and sample processing flowsheet

and chemical analysis results, aiming to investigate whether a mathematical relationship between the element concentrations and the compositions determined by sorting analyses can be found. This may open up the opportunity to create models that enable predicting specific chemical analysis parameters based on online or manual sorting analyses. The corresponding experiments were conducted from October to December 2018 in Allerheiligen im Mürztal, Styria, Austria.

\section{Materials and methods}

\section{Samples}

A replication experiment was carried out sampling approximately 45 metric tons of MCW from the area of Graz, Austria, collected in October 2018. The waste was coarsely shredded using a mobile single-shaft coarse shredder (Komptech Terminator 5000 SD with F-type cutting unit) operating at $18.6 \mathrm{rpm}$ (i.e., $60 \%$ of the maximum shaft rotation speed) and with a completely closed cutting gap. A wheel loader was used to feed the shredder that was slowly moving forward, forming a windrow of the discharge material via the shredder's discharge conveyor belt. A total of 200 sample increments (with a mass of $\sim 12 \mathrm{~kg}$ each) were taken from the falling waste stream at the end of the conveyor belt using sampling troughs (length $\mathrm{x}$ width $\mathrm{x}$ height: $1.17 \times 0.37 \times 0.30 \mathrm{~m}$ ) in time intervals of $30 \mathrm{~s}$. Ten composite samples (each with a mass of $\sim 240 \mathrm{~kg}$ ) were created by combining 20 sample increments taken in time intervals of $5 \mathrm{~min}$.

Each of the 10 composite samples was screened using a batch drum screen in multiple steps to generate 9 particle size fractions: $0-5 \mathrm{~mm}, 5-10 \mathrm{~mm}, 10-20 \mathrm{~mm}, 20-40 \mathrm{~mm}$, 40-60 mm, 60-80 mm, 80-100 mm, 100-200 mm, 200-400 mm. In total, 90 samples were generated. After each screen cut, the mass of the screen underflow was determined, and the sample mass was reduced, if appropriate, see Fig. 2. Every particle size fraction $>20 \mathrm{~mm}$ was manually sorted to determine the material composition and was reunited for chemical analyses. For details on the procedure and calculations, cf. Khodier et al. (2020).

\section{Chemical analyses}

All 90 samples were chemically analyzed, for detailed analysis results cf. Viczek et al. (2021b). The samples were dried to 
constant mass at $105^{\circ} \mathrm{C}^{1}$ to determine the dry residue according to EN 14346 (process A) (ASI 2007). Hard impurities (e.g., metal parts, stones) were removed to avoid damages to the mills. The removed impurities were weighed and can be accounted for in terms of their weight, but they were not separately analyzed, which corresponds to common laboratory practice (for a more detailed discussion, cf. Viczek et al. (2020)). The effects of this practice are discussed in "Handling of hard impurities" section. Further sample processing included comminution to a size $<0.5 \mathrm{~mm}$ using cutting mills, homogenization, and mass reduction.

Concentrations of silver (Ag), aluminum (Al), arsenic (As), barium $(\mathrm{Ba})$, beryllium $(\mathrm{Be})$, calcium $(\mathrm{Ca})$, cadmium $(\mathrm{Cd})$, cobalt $(\mathrm{Co})$, chromium $(\mathrm{Cr})$, copper $(\mathrm{Cu})$, iron $(\mathrm{Fe})$, mercury $(\mathrm{Hg})$, potassium $(\mathrm{K})$, lithium $(\mathrm{Li})$, magnesium $(\mathrm{Mg})$, manganese $(\mathrm{Mn})$, molybdenum $(\mathrm{Mo})$, sodium $(\mathrm{Na})$, nickel $(\mathrm{Ni})$, phosphorus $(\mathrm{P})$, lead $(\mathrm{Pb})$, palladium $(\mathrm{Pd})$, antimony $(\mathrm{Sb})$, selenium $(\mathrm{Se})$, silicon $(\mathrm{Si})$, tin $(\mathrm{Sn})$, strontium $(\mathrm{Sr})$, tellurium (Te), titanium (Ti), thallium (Tl), vanadium $(\mathrm{V})$, tungsten (W), and zinc ( $\mathrm{Zn}$ ) were determined by ICP-MS (based on EN 15411 (ASI 2011a) and EN ISO 17294-2 (ASI 2017)) after microwave-assisted acid digestion with hydrofluoric acid (HF), nitric acid $\left(\mathrm{HNO}_{3}\right)$, and hydrochloric acid $(\mathrm{HCl})$ (ÖNORM EN 13656 (ASI 2002)). Calorimetric digestion (ÖNORM EN 14582 (ASI 2016)) followed by ion chromatography (EN ISO 10304-1 (DIN, 2009)) was applied to determine the chlorine $(\mathrm{Cl})$ content. The lower heating value (LHV) was calculated according to DIN 51900-1 (DIN, 2000), and the ash content was determined according to DIN 51719 (DIN 1997). Samples were measured as duplicates.

\section{Handling of hard impurities}

EN 15443 (ASI 2011c) states that it is essential that all materials are included in the sample when the particle size is reduced, as, e.g., removing metals significantly influences the results regarding these and other accompanying metals. However, the tools for particle size reductions listed in the standard are not suitable for the comminution of hard materials to particle sizes suitable for preparing tests or laboratory samples. According to EN 15413 (ASI 2011b), different visible fractions can be separately analyzed when this procedure enhances subsequent comminution, homogenization, or

\footnotetext{
${ }_{1}^{1}$ Because of the volatility of elemental $\mathrm{Hg}$, EN 15411 proposes not to expose samples to temperatures above $40{ }^{\circ} \mathrm{C}$ before determining the $\mathrm{Hg}$ content. However, the waste samples that are subject to chemical analyses in this study have already passed several process steps (coarse shredding, sieving, laboratory scale comminution). Temperatures exceeding $40{ }^{\circ} \mathrm{C}$ therefore cannot be excluded, especially during comminution steps. For this reason, and because elemental $\mathrm{Hg}$ is also volatilized when the samples are dried at $40{ }^{\circ} \mathrm{C}$, the $\mathrm{Hg}$ that is determined in this study is somehow bound. Drying at $105^{\circ} \mathrm{C}$ is therefore considered suitable for this purpose.
}

sub-sampling processes. In the case of non-shreddable materials being present, the standard suggests manual separation. The mass of every removed fraction needs to be documented to enable reporting a weighted combination of analysis results.

Separately analyzing the hard impurities is often not a viable option when either the equipment is not available to laboratories or suitable comminution aggregates require a minimum filling amount that cannot be reached. In the area of solid recovered fuels, the most common approach is to account for these fractions of hard impurities only in terms of their weight, which means the analyte concentration is considered zero. This is a legit assumption when the analysis results are not affected by the impurity, e.g., for iron parts and the lower heating value (LHV), which technically is zero for metals. However, if the analytes are heavy metals, this practice leads to a distortion of results.

\section{Calculations and data analysis}

\section{Correlations and RSVs}

To interpret the correlation through significant Pearson correlation coefficients normally distributed data are necessary. Spearman correlation coefficients allow interpretations if the data are distributed differently. Therefore, the logarithmic normal distribution of each analyte (element, LHV), as well as the normal distribution $(\alpha=0.05)$ of the material fractions and log-ratios (see "Log-ratios" section) of the fractions, was tested separately in each particle size class above $20 \mathrm{~mm}$ using the Kolmogorov-Smirnov test (MathWorks 2020b) in MATLAB (version 9.6 R2019a). Statistically significant $(p<0.05)$ correlations (Pearson and Spearman coefficients) for elements and materials were calculated with RStudio ( $\mathrm{R}$ version 4.0.2) using only particle size fractions above $20 \mathrm{~mm}$, as the smaller fractions have not been manually sorted. Furthermore, the material classes "inert" and "metal" were excluded because they were not part of the chemical analyses. The detailed results of the sorting analyses summarized in Khodier et al. (2020) are given in Appendix E.

RSV values were calculated based on Formula 1 with concentrations (c) below the limit of quantification (L.O.Q.) being considered with $c=$ L.O.Q. Correlation coefficients (Pearson r, Spearman $\rho$ ) for RSVs with other parameters, e.g., particle size classes (using the mean value for each particle size fraction, e.g., $7.5 \mathrm{~mm}$ for the fraction $5-10 \mathrm{~mm}$ ) were calculated using OriginPro 2020 (version 9.7.0.188). The strength of the correlation was assessed based on Cohen (1988): strong $(|r|>0.5)$, moderate $(0.3<|r|<0.5)$, and weak correlation $(0.1<|r|<0.3)$. 


\section{Log-ratios}

To consider the fact that data from sorting analyses are compositional data providing information about relative values, log-ratios were calculated to interpret the influence on the element concentration of the varying composition of the material. In this case, the additive log-ratio transformation was used because it allows comprehensible interpretation for the given case since only two components are considered in one log-ratio. Here, one material fraction needs to be defined as the denominator of a set of logarithmic ratios (natural logarithms were used, following common practice) defined by the other material fraction as numerators (Greenacre 2019). In this case, each of the material fractions was once chosen as the denominator to allow to interpret the influence of all material fractions to each other individually, while the remaining fractions were used as the numerators, resulting in six ratios for each particle size class above $20 \mathrm{~mm}$, i.e., the samples that were manually sorted. Similar to the interpretation of element-material correlations, the fractions "metal" and "inert" were not considered in the calculation since they were removed before chemical analyses. In general, "zero values" are problematic in a dataset for computing ratios, but several different options for replacing the zeros are available. In the given case, zero values were only present in the particle size class $200-400 \mathrm{~mm}$ in the material fractions wood, paper, and cardboard (see Appendix E), and they were replaced with the small value 0.005 , which is a common method according to Greenacre (2019) (if a larger amount of zero values is present, a sensitivity analyses can be conducted to compare the effect of different zero replacement methods). With this adaption, the data were rescaled to $100 \%$, which in the field of compositional data is called "closing the data" (Greenacre 2019) for the following calculations. To compare and interpret the correlations between material fractions and element concentration, the results were calculated in RStudio and consider the log-ratios of the material fractions and the element concentrations. The latter were calculated as logarithmic values (natural logarithm) for interpretation purposes.

\section{Prediction models for element concentration and LHV}

The prediction models aim to project the element concentration without chemical analysis, based on the information of material composition only, and are a possibility to combine the information from Part I and the results from the present paper. Since only materials above $20 \mathrm{~mm}$ were sorted in separate material classes, prediction models were only built considering the six particle size classes in 20-400 mm (20-40 mm, 40-60 mm, 60-80 mm, 80-100 mm, $100-200 \mathrm{~mm}, 200-400 \mathrm{~mm}$ ). Since prior investigations during this work confirmed highly correlated multi-dimensional data, the partial least squares regression (PLS) was chosen.
It enables to build a linear regression model from the original data by transforming the data in a new space, with the option to reduce dimensions for easier visualization. To find the ideal number of considered dimensions (factors), different approaches are possible. Here, the criterion was to consider the number of factors that lead to the smallest predicted residual sum of squares (PRESS) (Vandeginste et al. 1998) in the process of cross-validation. Cross-validation (CV), in general, is an option to evaluate the performance of the model and can be done in various ways. The underlying principle of all CV options is to split the dataset into two groups. One is used to build the model (calibration data), and the rest is used for evaluation (test data). Most methods use multiple rounds of $\mathrm{CV}$ to reduce variability by building different calibration and test datasets and calculate a combined result for the validation result over all the rounds (Massart et al. 1997). Since the given dataset, in this case, has a rather small amount of entries ( 31 measurements for 60 samples), the CV method "leave-one-out" was chosen. Here, one entry was chosen to be the test data, while the model was built on the residual data, and the PRESS for each considered dimension was calculated as the average of all rounds. From this, the ideal number of factors was evaluated by finding the value corresponding to the lowest PRESS, which was then used in MATLAB (version 9.6 R2019a) with the function "plsregress" (MathWorks 2020c) to build the regression model and calculate regression coefficients. A list of the number of considered factors for each element is given in Appendix C. Esbensen et al. (2018) critically discuss the influence of the chosen number of rounds in each cross-validation on the model outcome. When considering the error of the model as a criterion for selecting the ideal number of factors, it must be noted that the model error decreases with an increase of rounds. Additionally, attention must be paid to select the ideal number of rounds. Different fields of research often prefer a different number of rounds, but for the best results, Esbensen et al. (2018) recommend investigating $\mathrm{CV}$ with a different number of rounds and comparing the validation results with each other for similarity. Hence, the chosen CV approach is not ideal in general, but necessary in this case due to the limited size of the dataset. With the underlying idea of developing a model for replacing chemical analyses with the involved sampling and preparation steps, the models were firstly built from the data for all particle size classes combined. It was found that the overall results highly improve when considering the particle size classes individually, due to the high variability of the element concentration in the individual particle size classes (see "RSV and GEE" section). This led to the development of six prediction models per element, which can predict the concentration of 29 individual elements (see "Chemical analyses" section, without $\mathrm{Be}, \mathrm{Pd}, \mathrm{Se}, \mathrm{Te}, \mathrm{Tl}$ (because values were mostly below L.O.Q.)) as well as the LHV based on the information from the calculated log-ratios. 
In the case of the prediction model, the fraction of 3D-plastics was chosen as the denominator for the log-ratios since it showed plausible results in the correlation plot, while the fractions cardboard, paper, textile, wood, 2D-plastics, and residual fraction were used for the numerators. This resulted in six ratios for each particle size class above $20 \mathrm{~mm}$, i.e., manually sorted fractions. Elements with concentrations $<$ L.O.Q. were considered with the value for L.O.Q. to consider as many values as possible for the regression model. Especially for the elements $\mathrm{Cd}$ and $\mathrm{Hg}$, a large proportion of the measured values was below L.O.Q. in the larger particle size fractions. Pd was overall excluded from the prediction because the chemical analysis found over $90 \%$ (cf. Viczek et al. 2021b) of the available values to be below L.O.Q., which would not allow a meaningful prediction. To further allow to find a model with good prediction purposes in most cases, outliers of the available element concentrations were removed for the creation of the model. These were identified when the value was more than three scaled standard median absolute deviations away from the median (MathWorks 2020a). In general, ten data points for each regression model were available, but because outliers were excluded for building the models, a smaller amount of data points was left in some cases. The minimum number of values necessary for the model was set to seven, since it allows to calculate and interpret the median values, which concluded that a prediction model was not possible for all elements in all particle size classes (e.g., $\mathrm{Cr}(200-400 \mathrm{~mm}$ ) and $\mathrm{Sn}(80-100 \mathrm{~mm})$ ). A list with the number of the available datasets is given in Appendix C. The accuracy of the models was tested with the same data that was used to build the models. This is not an ideal approach to assess the models' prediction abilities but was necessary since only a limited number of analyses were available.

\section{Results and discussion}

\section{Possible incorrect sampling errors}

Measures were set to minimize and eliminate incorrect sampling errors where possible during and after the experiment. However, due to the on-site circumstances and the duration of sample processing and analysis, IEE and especially IPE cannot be entirely excluded. Incorrect sampling errors during primary sampling, mass reduction, screening, and sorting were already discussed in Part I (Khodier et al. 2020). The loss of material and possible contamination of containers and equipment on-site were briefly discussed as well but require a more detailed discussion because these factors play an essential role in chemical analyses.

\section{Material and water loss}

One of the main IPEs occurring is the bias caused by material loss. Material may have been lost in the form of dust (e.g., during screening) or as single particles during sorting. This loss likely influences the analysis results as the dust may have contained the determined elements in different concentrations than the rest of the waste stream. Furthermore, water loss has occurred during the time-intensive sample processing and sorting steps. The water content of the primary sample or each particle size fraction was not determined directly, but in the laboratory, i.e., after several on-site processing steps (screening, sorting) and storage. For this reason, the exact water content at the time of the sampling is unknown. The extent of the water loss is expected to differ for each particle size fraction because of different processing steps. The small fractions $<20 \mathrm{~mm}$ were not sorted and were transported and stored in buckets with sealable lids (after being stored in closed disposal bins on-site). Particle size fractions $>20 \mathrm{~mm}$ were sorted, which was a time-consuming process. Because the sorting process of smaller particle size classes took longer, more water evaporation is expected to have taken place for smaller particle size fractions than larger ones. After being stored in closed disposal bins on site as well, these fractions were transported and stored in closed garbage bags before analysis. Consequently, it is assumed that the small fractions $<20 \mathrm{~mm}$ have experienced the smallest water loss. However, in contrast to the loss of dust, the IPE caused by water loss does not influence analysis results for chemical elements as they refer to $\mathrm{mg} / \mathrm{kg}$ dry mass (DM).

IPEs caused by material and water losses, however, may influence the calculations of the overall analyte concentration in the initial waste mix or calculations regarding the removal of specific fractions (cf. Viczek et al. 2021b). The water evaporated during screening and sorting is not accounted for by the determination of the water content in the laboratory. This may lead to underestimating the water content for fractions $>20 \mathrm{~mm}$ based on the laboratory results and may cause an overestimation of the total load of an element in the larger fractions. For this reason, the concentrations in the waste mix were calculated using the final fraction weights after sorting instead of the fraction weights after screening. Because of the IPE caused by material and water loss, however, the exact original composition is unknown. With a total mass loss (i.e., dust, water) between screening and the final sorting results of $5.6 \%$ on average (range $4.6-7.2 \%$ ), the losses are manageable.

\section{Contamination of on-site equipment}

Another critical incorrect sampling error is possible contamination during sample processing, as the containers and equipment on-site could only be cleaned using hand brushes. Cross-contamination between the 10 representative samples 
Fig. 3 Share of each element [\%] in the different particle size classes. The elements are colored according to the groups identified in Viczek et al. (2021b) based on the observed statistically significant $(p<0.05)$ correlations for $\ln$ (particle size) and $\ln ($ element concentration). Pattern A: strong $(r>0.5$, dark blue), moderate $(0.3>r>0.5$, lighter blue) or weak $(0.1>r>0.3$, turquoise) negative correlation. Pattern B: no statistically significant correlation (light green, only observed for $\mathrm{Cd}$ ). Pattern $\mathrm{C}$ : positive correlation (beige)

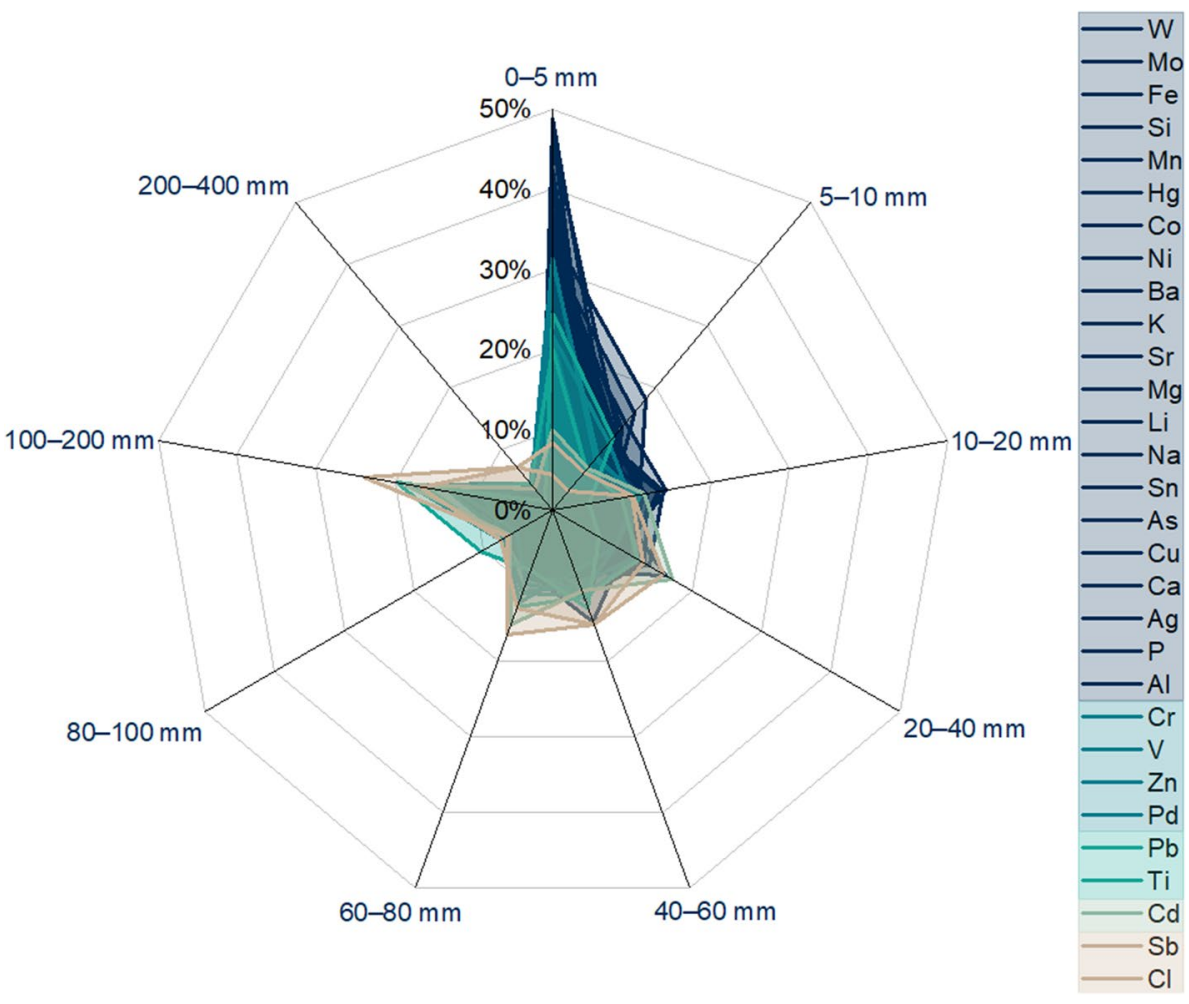

and sub-samples (particle size fractions) — all originating from the same pile of waste-can therefore not be excluded entirely. However, potential contaminations are expected to be low due to small contact areas in relation to the sample masses.

\section{Chemical analyses and subsampling}

In addition to the possible errors discussed above and in Part I, additional sampling errors in Part II include sample processing in the laboratory (including subsampling) and the total analytical error (TAE). Besides the removal of hard impurities, which was discussed in "Handling of hard impurities" section, the errors occurring in the laboratory include the potential loss of analytes, for example, the potential loss of $\mathrm{Hg}$ while drying the samples in the oven at $105^{\circ} \mathrm{C}$, see "Chemical analyses" section for a brief discussion of this issue. However, as the volatility of $\mathrm{Hg}$ is well known, this error needs to be considered when interpreting the results, as is the case for hard impurities. Further errors may be caused by incomplete digestion, which was counteracted by choosing microwave-assisted acid digestion with $\mathrm{HNO}_{3}$, $\mathrm{HCl}$, and $\mathrm{HF}$. Other errors that may occur, e.g., by subsampling, contamination by mills, were minimized by good laboratory practice in the EN ISO/IEC 17025 accredited laboratory performing the sample preparation and analyses.

\section{Particle size-dependent distribution of elements}

The analysis results for 30 elements, which the calculations in the present paper are based on, are presented in detail and discussed with respect to SRF production in Viczek et al. (2021b). Four elements were mostly below the limit of quantification (L.O.Q.: Be, Se: $2.5 \mathrm{mg} / \mathrm{kg}_{\mathrm{DM}}$; Te, Tl: $0.25 \mathrm{mg} / \mathrm{kg}_{\mathrm{DM}}$ ). Viczek et al. (2021b) identified three different groups based on the observed correlation patterns between $\ln$ (particle size) and $\ln$ (element concentration), see Fig. 3. A negative correlation between element concentrations and the particle size was the predominant pattern observed for 27 of the 30 investigated elements. The fine fraction $<5 \mathrm{~mm}$ was found to contain the highest concentrations and most considerable total amounts of these elements. The different distribution of these elements among different particle size classes, their industrial applications, and the corresponding implications regarding heterogeneity-induced sampling errors are expected to influence the observed RSVs, see "RSV and GEE" section.

\section{RSV and GEE}

Relative sampling variabilities (RSVs) were calculated for five cases: $\mathrm{mg} / \mathrm{kg}_{\mathrm{DM}}$ without hard impurities, $\mathrm{mg} / \mathrm{kg}_{\mathrm{DM}}$ including hard impurities, $\mathrm{mg} / \mathrm{kg}_{\mathrm{OS}}$ including hard impurities, $\mathrm{mg} / \mathrm{MJ}$, and for the percentual share of the element concerting the total mass of the primary sample (dry mass without hard 


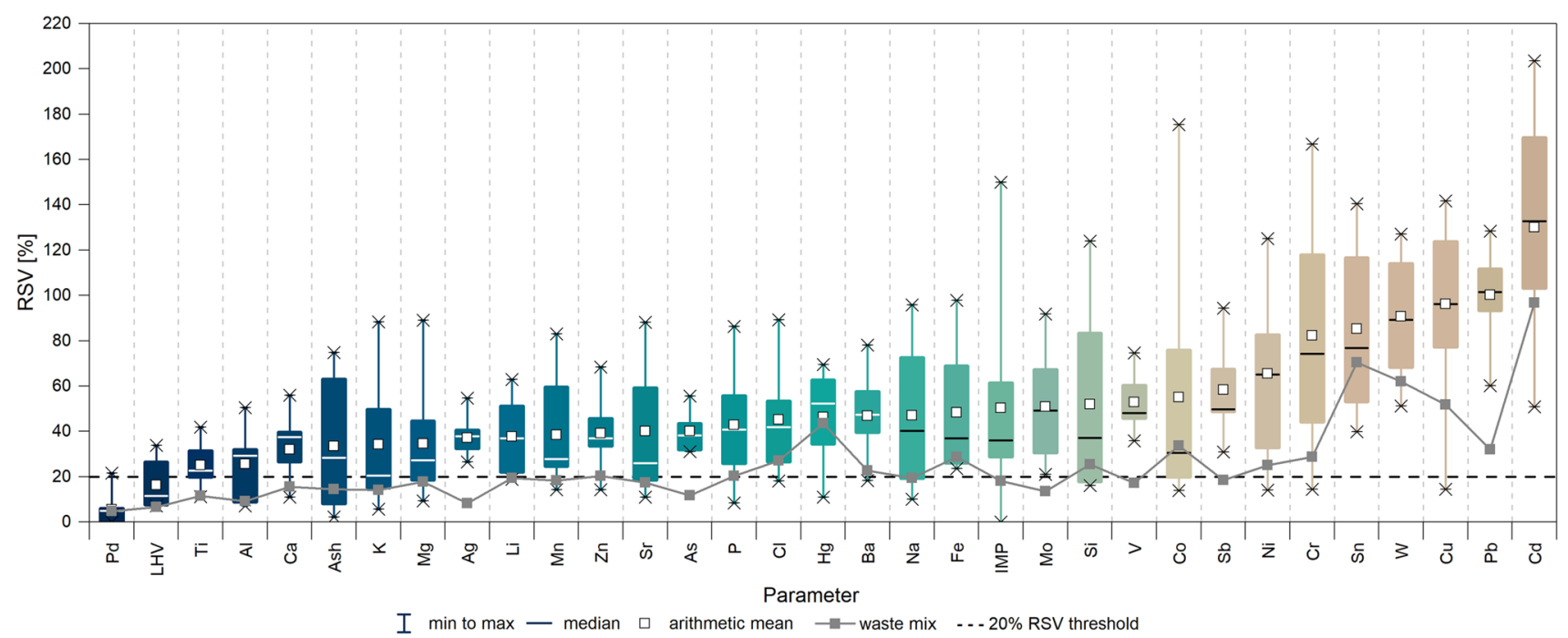

Fig. 4 RSVs of element concentrations, LHV, ash content, and hard impurities (IMP) in the different particle size classes sorted from low to high RSVs based on their mean RSVs. The solid gray line repre- sents the RSVs for element concentrations in the whole waste mix, i.e., of the united particle size fractions

and around 35-42 MJ/kg $\mathrm{DM}_{\mathrm{DM}}$ for PS, PE, and PP (Viczek et al. 2021a; Weissenbach and Sarc 2021). This indicates that the LHV of the most abundant materials in waste only differs by a factor of 2-3.

The low RSVs for Ti, in contrast, may be linked to its presence in similar concentrations among all particle size fractions (cf. Viczek et al. 2021b), indicating that the element is well distributed in the waste material. This is likely to result from the broad range of applications of titanium dioxide $\left(\mathrm{TiO}_{2}\right)$, which is present in most white or brightly tinted items, including paints, plastics, fibers, paper or cardboard, enamels, or ceramics (Holleman et al. 2007).

The example of Ti highlights the role distributional heterogeneity plays for chemical analyses of waste. The results of the elements for which the highest RSVs were observed additionally strongly reflect the large effect of constitutional heterogeneity. As illustrated in Fig. 4, the highest RSVs were observed for $\mathrm{Cd}$, followed by $\mathrm{Pb}, \mathrm{Cu}, \mathrm{W}, \mathrm{Sn}$, and $\mathrm{Cr}$. Concentrations of all these elements were highly variable in almost all particle size fractions. These elements are not broadly present in all typical materials occurring in waste but rather occur in high concentrations in specific materials or particles (cf. Viczek et al. 2020), which means a high constitutional heterogeneity is expected. For example, the $\mathrm{Cu}$ concentration in a copper wire fragment is a lot higher than in the surrounding particles. Consequently, single fragments of copper wire ending up in the sample significantly alter the analysis results. The case is similar for $\mathrm{Cd}$, as it was formerly used as a pigment or stabilizer in plastics but has been banned for this purpose in the European Union (EC 2011). Therefore, it will be less abundant in plastic items that were produced in Europe more recently. As both distributional and constitutional board; around 20-25 MJ/kg for PET, PVC, and textiles; 
Fig. 5 RSVs of all parameters (excluding Pd, water content, and impurities) for different particle size classes

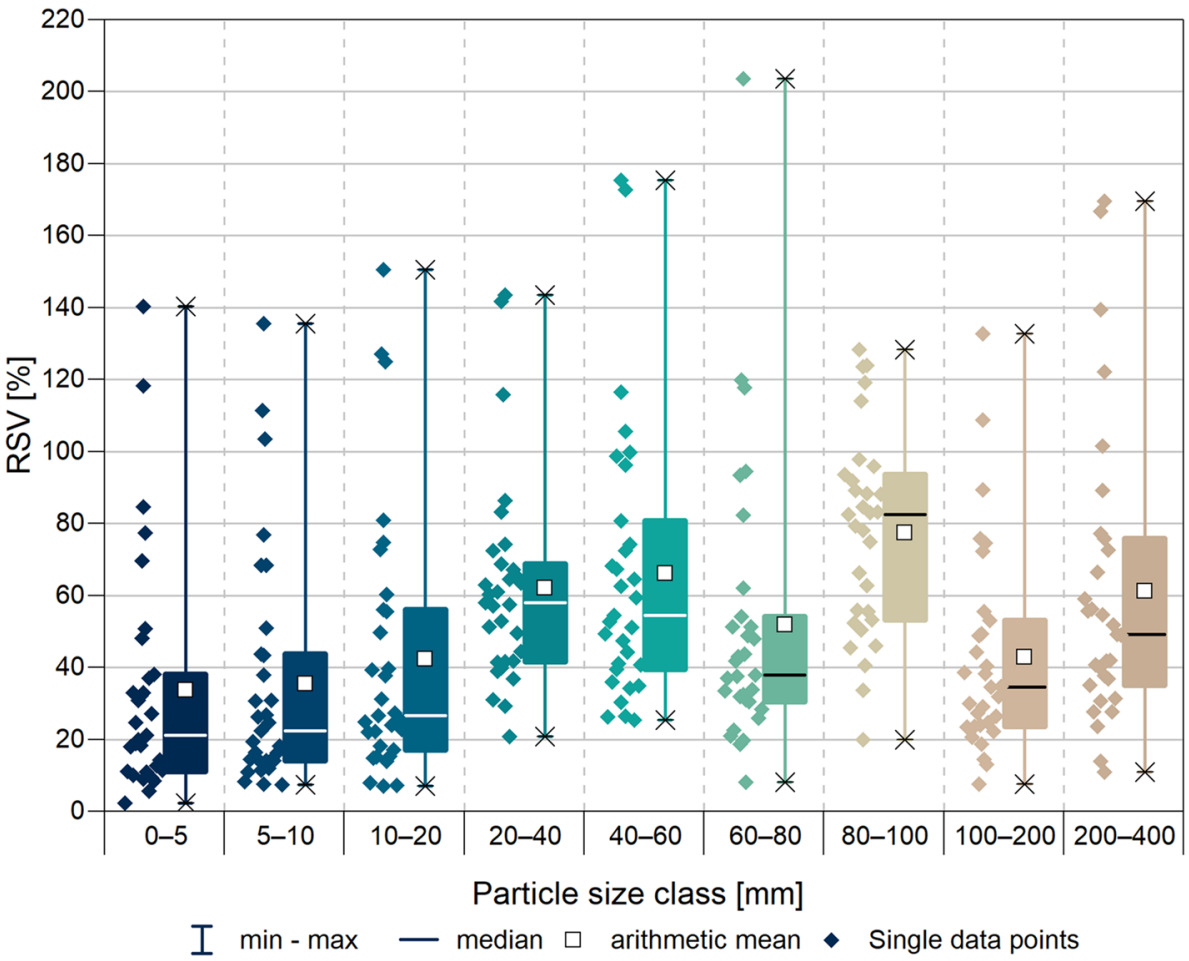

heterogeneity causes correct sampling errors, it has to be assumed that the correct sampling error and, consequently, the minimal possible error (MPE) are already high for certain chemical elements in mixed commercial waste analyses. For this reason, the sampling can only be improved with higher efforts (e.g., increasing the number of increments, increasing the total sample mass).

\section{RSVs for different particle size classes}

The smallest particle size fractions $<20 \mathrm{~mm}$ exhibit slightly better RSVs than larger fractions, indicating a better sampling quality for smaller particle size fractions (Fig. 5). The worst median RSVs are observed for the fraction 80-100 $\mathrm{mm}$. Linear correlation analysis of $\ln$ (particle size) vs. $\ln (\mathrm{RSV})$ confirms that there is a statistically significant $(p<0.05)$ moderate positive correlation (Pearson $r=0.37$, Spearman $\rho=0.31$ ) between the particle size and the RSV. Furthermore, a weak ( $r=-0.17, \rho=-0.12)$ but statistically significant $(p<0.05)$ negative correlation between the mass share of the particle size fraction and the RSV is observable, indicating that the RSV of element concentrations in a particle size fraction decreases with increasing mass shares of the particle size fraction. This is consistent with the observations reported in Part I, although a much smaller proportion of the initial sample mass was ultimately subject to chemical analyses.

However, higher concentrations alone do not cause better RSVs, as there is no statistically significant correlation between the RSV and the element concentration (average concentration in the particle size fraction in relation to the maximum observed average concentration: $\left.c_{\mathrm{i}} / c_{\max }\right)$.

\section{RSVs calculated for the original waste mix}

Combining the different particle size classes and calculating the RSVs for the overall concentrations of each element in the waste mix (gray line in Fig. 4) shows that despite the high RSVs in single fractions, good RSVs $<20 \%$ can be achieved for 15 of 30 elements $\left(\mathrm{mg} / \mathrm{kg}_{\mathrm{DM}}\right)$ and the LHV, impurities, ash content, dry matter, and water content (Table A.6 in Appendix A). RSVs between 20 and 50\% can be achieved for 11 elements. These RSVs are achieved even though the single fractions underwent additional processing (screening, sorting) and are therefore affected by additional errors, which leads to the suggestion that even better RSVs can be achieved when the original samples are directly analyzed.

\section{Mathematical relations for elements and material fractions}

\section{Interpretation of correlations via correlation plot}

Statistically significant $(p<0.05)$ correlations between chemical elements, LHV, and the mass share of materials listed in Appendix E (excluding metals and inert materials, see 


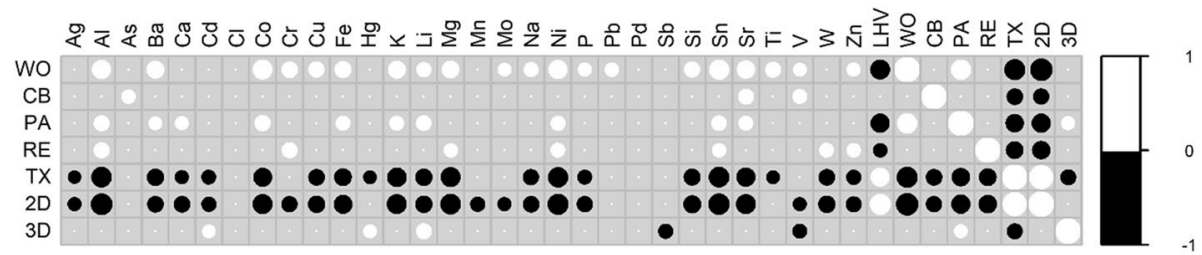

Fig. 6 Statistically significant $(p<0.05)$ positive (white) and negative (black) Spearman correlations of analysis parameters and sorting analyses for particle size classes $>20 \mathrm{~mm}$ from Part I (Khodier et al. 2020). The size of the circles is proportional to the strength of the linear correlation (for numbers of Pearson and Spearman correlation coefficients see Appendix B). Abbreviations: cardboard (CB), paper (PA), textile (TX), wood (WO), 2D-plastics (2D), 3D-plastics (3D), residual fraction $(\mathrm{RE})$

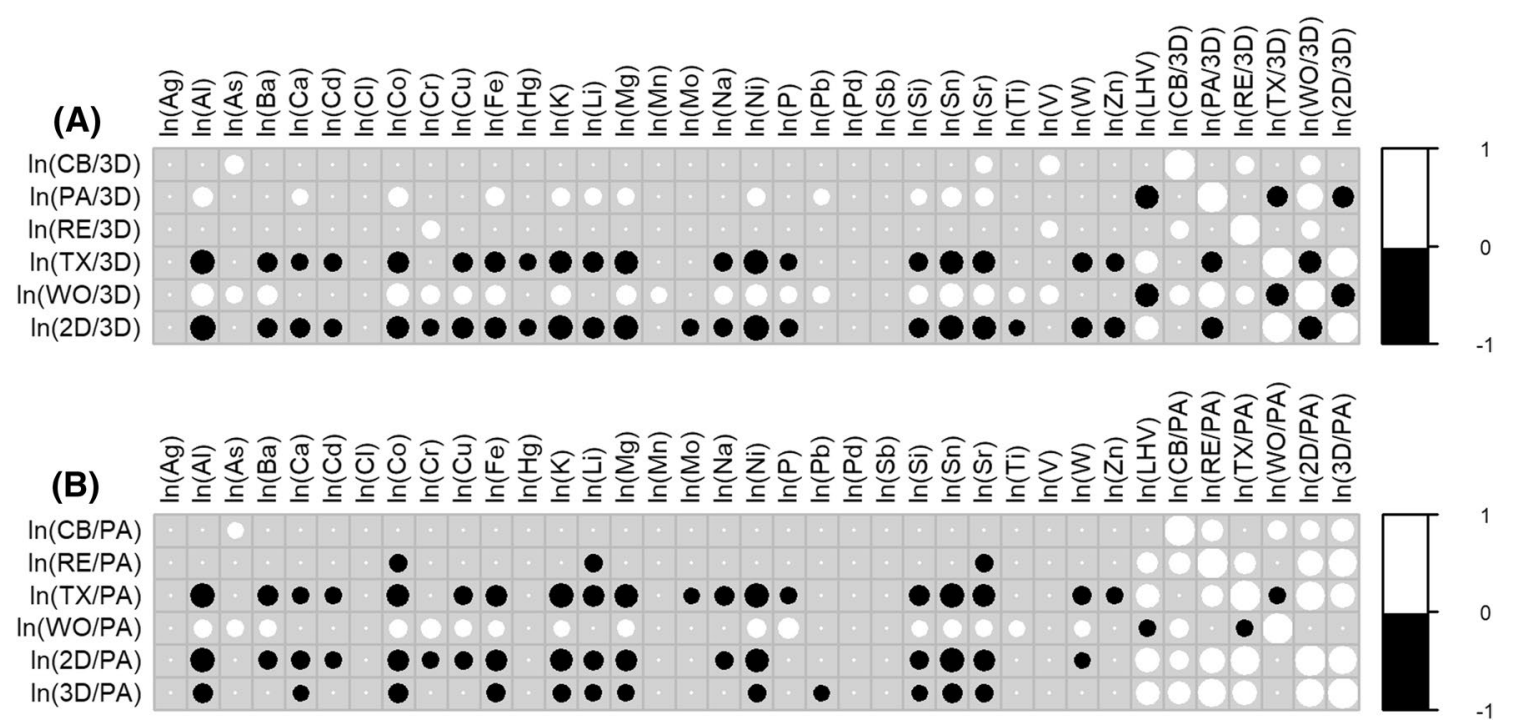

Fig. 7 Statistically significant $(p<0.05)$ positive (white) and negative (black) Spearman correlations of logarithmic values of the analysis parameters and log-ratios based on results from sorting analyses for particle size classes $>20 \mathrm{~mm}$ from Part I (Appendix E) with the reference material $\mathbf{a} 3 \mathrm{D}$ and $\mathbf{b} \mathrm{PA}$. The size of the circles is proportional to

"Handling of hard impurities" section) in the particle size classes above $20 \mathrm{~mm}$ are presented in Fig. 6. The correlation plot shows, inter alia, a negative correlation of the LHV with wood (WO), paper (PA), and the residual fraction (RE), and a positive correlation with 2D plastics (2D) and textile (TX). This may lead to the interpretation that a higher share of wood, paper, and residuals leads to a lower LHV, and a larger share of 2D plastics and textile increases the LHV, while the amount of 3D plastics (3D), as well as cardboard (CB), does not significantly influence the LHV. While the correlation between $2 \mathrm{D}$ plastics and the LHV is consistent with the observation that the LHV of waste plastics (especially PE from foils) is usually higher than that of wood, paper, or cardboard (Weissenbach and Sarc 2021), attention has to be paid to the fact that data from sorting analyses are compositional data. Therefore, the decrease of the LHV might not be entirely attributable to the increase of the mass fraction of wood, paper, and residuals, but rather to the fact that the the strength of the linear correlation (for numbers of Pearson as well as Spearman correlation coefficients see Appendix B). Abbreviations: cardboard (CB), paper (PA), textile (TX), wood (WO), 2D-plastics (2D), 3D-plastics (3D), residual fraction (RE)

increase of their share (in \%) results in a decrease in the share (in \%) of other materials, e.g., plastics 2D and 3D. This is also shown by the calculated log-ratios for the material fractions (Fig. 7, full results given in Appendix B), as strong negative correlations between the material ratios $\mathrm{PA} / 3 \mathrm{D}, \mathrm{WO} / 3 \mathrm{D}$, and the LHV are observed, indicating a lower LHV when the share of PA or WO is increasing compared to the amount of 3D (Fig. 7a). These observations are also consistent with the report of Weissenbach and Sarc (2021), as many of the plastics that may be present in the 3D fraction (e.g., PE, PP, PS) feature a higher LHV than wood and paper.

Additionally, Fig. 7b indicates a decreasing LHV when the share of WO increases compared to the share of PA. This statement contradicts literature results (e.g., Beilicke and Wesenigk 1987; Weissenbach and Sarc 2021) and makes an interpretation of compositional data only based on the correlation plots complex. Further, Fig. 7a shows that a higher share of wood compared to plastics 3D leads to a larger amount 
of $\mathrm{Al}$ in the sample. At the same time, the ratios $\mathrm{CB} / 3 \mathrm{D}$, as well as $\mathrm{PA} / 3 \mathrm{D}$ and $\mathrm{RE} / 3 \mathrm{D}$, are positively correlated with the ratio $\mathrm{WO} / 3 \mathrm{D}$. With this additional information, the increasing amount of $\mathrm{Al}$ cannot be clearly assigned to a rising share of wood in the sample but might also arise from the paper and/ or cardboard and/or residual fraction. This is consistent with the literature review of Götze et al. (2016), indicating that the median $\mathrm{Al}$ concentrations in waste plastics are usually lower than in paper, gardening waste, combustibles, and the waste mix, suggesting that the observations in Fig. 7 may be connected to the low $\mathrm{Al}$ content of plastics. This emphasizes again that interpretations are possible, but their complexity often requires additional research and evaluation methods. Nevertheless, the results from the prediction models in "Possibilities for prediction models for element concentration and LHV" section state that the correlation between elements and material fractions is, in most cases, sufficient to forecast specific element concentrations for the median value.

\section{Possibilities for prediction models for element concentration and LHV}

To show the mathematical relation between element concentrations and sorting analyses, in total, prediction models for 29 elements and the LHV in six particle size classes were obtained. The log-ratios as observable variables, the original measured value of the element concentration as the predicted variable, as well as the ideal number of considered factors (based on cross-validation, see "Prediction models for element concentration and LHV" section) served as the input for the models. As an immediate result, the models calculated regression coefficients for predicting values for new data. The regression coefficients $k$ for the individual models are given in Appendix $\mathrm{C}$ and are used in Eq. (2) for calculating the element concentration or the LHV. Here, the calculated concentration $c_{j_{P S C}}$ of element $j$ in the particle size class $P S C$ is defined by the regression coefficients $k$ and log-ratios for the material fractions $w_{i, P S C}$.

$c_{j_{\mathrm{PSC}}}=k_{0, \mathrm{PSC}}+\sum_{i} k_{i, \mathrm{PSC}} * \ln \left(\frac{w_{i, \mathrm{PSC}}}{w_{3 D, \mathrm{PSC}}}\right)$

For the evaluation of the models, all the available data (including datasets that were previously identified as outliers) were applied to the models, and the calculated/predicted value of the element concentration/LHV was compared with the chemically determined value due to a limited number of samples (10 replicates). Additionally, the results for the predicted values in the whole sample in all particle size classes above $20 \mathrm{~mm}$ were calculated and compared with the original value as well. The results are presented in box plots, where each predicted value was compared with the original one $\left(y_{\mathrm{fit}} / y\right)$ to show the accuracy of the models in percent. Taking $\mathrm{Fe}$ as an example, Fig. 8 shows that most of the predicted Fe values for all particle size classes reach the original value in a range of $\pm 20 \%$. Additionally, the mean values, as well as the median values, lie within that range too. The plots for the remaining elements as well as the LHV are given in Appendix D. As a summarized result of the models, the median values from the ten available samples for the reached percentage of the predicted values are presented in Table 1. Except for $\mathrm{Ba}, \mathrm{Cd}, \mathrm{Cl}$, $\mathrm{Cu}, \mathrm{Mo}, \mathrm{V}$, and $\mathrm{W}$, all the medians for the individual particle size classes (20-40 mm, 40-60 mm, 60-80 mm, 80-100 mm, $100-200 \mathrm{~mm}, 200-400 \mathrm{~mm}$ ) are in a range of $\pm 20 \%$ of a correct prediction, and the majority is even in a range of $\pm 10 \%$. Considering the median values of the material mix with the particle size $20-400 \mathrm{~mm}$, an even better accuracy was reached for most elements. By taking into account the median of the material mix, this approach would likely be the most practicable, e.g., for production plants of solid recovered fuels, since the quality must be defined for the overall output mix. Additionally, investigations for the consideration of the material fractions below $20 \mathrm{~mm}$ are required since they contain a high concentration and a large total amount of the analyte (Viczek et al. 2021b). Besides the quantitative determination of the element content, the technical limitations for optical detection of fine particles also require further research. Here, except for the elements $\mathrm{Cd}, \mathrm{Cr}, \mathrm{Cu}, \mathrm{Ni}, \mathrm{Pb}, \mathrm{Sn}$, the prediction of the median was approximately between 80 and $100 \%$ $(\mathrm{Cr}, \mathrm{Sn}$ : no values because of too little available values for regression model). This clearly states that there is a relation between material composition and element concentration and a possibility to estimate the results from chemical analysis mathematically by just the information from sorting analyses. According to the literature from Krämer (2017), real-time measurements from NIR technology deliver insufficient quantitative analyses for several heavy metals $(\mathrm{Cd}, \mathrm{Cr}, \mathrm{Sb}, \mathrm{Pb})$. The presented method results show poor quality for the prediction of $\mathrm{Cd}$ and $\mathrm{Pb}$ in the material mix (20-400 mm, median value). This is probably linked to their uneven distribution, which is also reflected by the fact that the highest RSVs were calculated for these two elements (see "RSV and GEE" section). For Sb, in contrast, an over $80 \%$ accuracy in predicting the concentration of $\mathrm{Sb}$ in the material mix was achieved. Due to the high number of outliers, no regression model for the overall value in the material mix of $\mathrm{Cr}$ could be built. The evaluation of the concentration of $\mathrm{Cl}$ and the LHV over NIR technology was significantly better than for the heavy metals in the results from Krämer (2017). The determined results from the models also showed very good accuracy for the values from LHV in all particle size classes, and in most cases, for $\mathrm{Cl}$. 


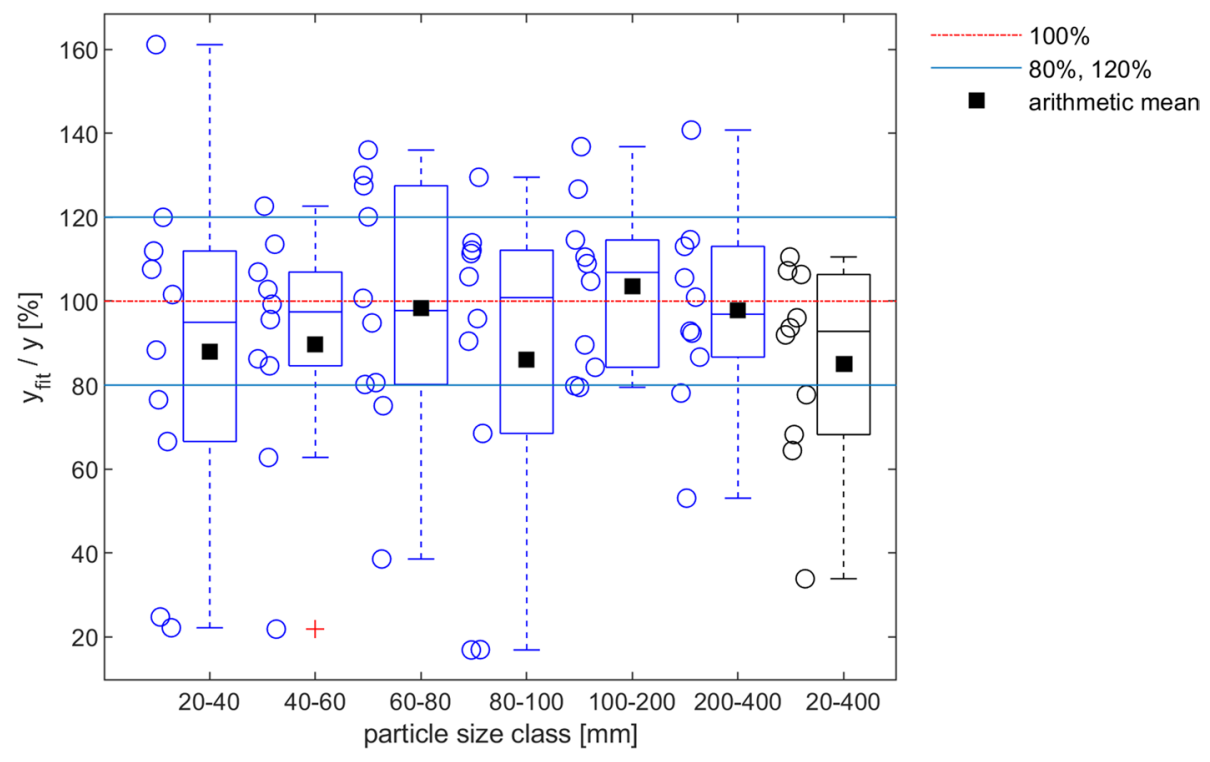

Fig. 8 Box plot of iron $(\mathrm{Fe})$ for the results of the prediction models in different particle size classes and the material mix in the particle size classes $>20 \mathrm{~mm}$. Here, the boxes in the diagrams show the range from the 25th (lower quartile) to the 75th (upper quartile) percentile of the values, while the horizontal line inside the box defines the

\section{Study limitations}

The used dataset in this example is limited in its size, which is not typical for prediction models and shows in some cases a broad scattering of the values, which is typical for the considered waste material and its heterogeneity. However, such a detailed chemical analysis of a broad range of chemical elements and analytical parameters is rarely available for waste materials and a good opportunity to investigate the connections and correlations mentioned in the present article. Overall, the results show that a correlation between material composition and element concentration is recognizable, which might allow calculating chemical parameters based on information from, e.g., an NIR sorter combined with a model for sensor-based particle size determination. The latter was investigated on single particles in a mixed commercial waste stream by Kandlbauer et al. (2020). This combination could enable the evaluation of chemical properties without the expensive and time-consuming act of sampling, sample preparation, and chemical analysis since the information regarding material and particle size from NIR sorters and sensor-based particle size determination models could be evaluated, while the material is still in the treatment process (in-line analytics). Here, the necessity of in-line analytics is also reflected by the fact that the results from the prediction models are best for the median values of the individual samples, requiring a large number of samples for a good prediction of the actual values. Additionally, median. The whiskers, which are the extending vertical lines from the boxes, indicate variability outside the upper and lower quartile and consider a range for data points within the 1.5 interquartile range. Outliers are marked with a '+' -symbol, and additionally, the mean of each box plot, as well as the individual data points, is plotted

in-line analytics would allow timely results which, combined with suitable actuators in a processing plant, further enable influencing the quality and reacting to certain deviations by adapting treatment steps (screening, shredding).

Further investigations must deal with the fact that fine materials below $20 \mathrm{~mm}$ were not considered in the models but will contribute significantly to the heavy metal and metalloid content in waste samples. Here, methods to detect or determine the influence of particles that are smaller than a critical size determined by the camera resolution must be examined or may be considered with a correction factor in the models (Krämer 2017). Additionally, fractions with smaller particle sizes could be removed by a prior screening step, which would result in a decrease of the concentrations of most elements in the screen overflow. However, treatment options for the removed material streams need to be investigated (Viczek et al. 2021b, c).

\section{Conclusion}

While the applied procedure gives good results for some parameters, RSVs range up to $203.5 \%$ for others. This may be linked to the high distributional and constitutional heterogeneity caused by the industrial applications of the chemical elements and their compounds, leading to a high minimum possible errors (MPE) for these elements. However, better RSVs were achieved when calculated for the original waste stream rather than the single fractions, which would be the 
Table 1 Median of the ratios between the predicted values and the original one $\left(\boldsymbol{y}_{f i t} / \boldsymbol{y}\right)$ for the individual particle size classes and elements (values in \%)

\begin{tabular}{|c|c|c|c|c|c|c|c|}
\hline Element & 20-40 (mm) & $40-60(\mathrm{~mm})$ & 60-80 (mm) & $80-100(\mathrm{~mm})$ & 100-200 (Mm) & $200-400(\mathrm{~mm})$ & $20-400(\mathrm{~mm})$ \\
\hline $\mathrm{Ag}$ & 104.9 & 100.3 & 99.3 & 101.3 & 100.6 & 100.4 & 94.4 \\
\hline $\mathrm{Al}$ & 98.1 & 99.0 & 97.3 & 99.1 & 103.4 & 112.6 & 101.3 \\
\hline As & 106.0 & 106.6 & 105.1 & 111.6 & 102.4 & 104.1 & 101.2 \\
\hline $\mathrm{Ba}$ & 97.7 & 95.7 & 99.4 & 94.3 & 122.1 & 90.5 & 87.9 \\
\hline $\mathrm{Ca}$ & 96.6 & 98.9 & 102.6 & 119.2 & 96.7 & 97.2 & 97.1 \\
\hline $\mathrm{Cd}$ & 85.8 & 93.9 & 90.4 & 94.7 & 59.8 & 100.0 & 39.0 \\
\hline $\mathrm{Cl}$ & 100.5 & 94.6 & 103.3 & 95.2 & 79.9 & 104.5 & 89.5 \\
\hline Co & 93.9 & 100.5 & 102.8 & 97.7 & 99.6 & 98.0 & 94.0 \\
\hline $\mathrm{Cr}$ & 90.3 & 88.8 & 102.5 & 104.3 & 92.4 & - & - \\
\hline $\mathrm{Cu}$ & 67.8 & 82.6 & 99.5 & 81.3 & 103.5 & 95.7 & 60.2 \\
\hline $\mathrm{Fe}$ & 95.0 & 97.5 & 97.8 & 100.8 & 106.9 & 96.9 & 92.8 \\
\hline $\mathrm{Hg}$ & 96.9 & 100.0 & 100.0 & 100.0 & 100.0 & 100.0 & 92.84 \\
\hline K & 96.0 & 99.6 & 102.7 & 98.1 & 102.1 & 94.6 & 93.7 \\
\hline $\mathrm{Li}$ & 102.9 & 91.5 & 94.8 & 96.1 & 100.3 & 99.7 & 89.3 \\
\hline $\mathrm{Mg}$ & 93.9 & 98.2 & 97.9 & 90.7 & 95.7 & 99.3 & 94.3 \\
\hline $\mathrm{Mn}$ & 99.1 & 101.9 & 106.0 & 90.7 & 100.0 & 97.9 & 93.1 \\
\hline Mo & 97.8 & 98.7 & 108.3 & 96.4 & 112.5 & 124.3 & 91.4 \\
\hline $\mathrm{Na}$ & 91.5 & 99.9 & 101.8 & 99.1 & 93.6 & 117.1 & 88.0 \\
\hline $\mathrm{Ni}$ & 95.7 & 96.7 & 98.4 & 93.5 & 102.3 & 99.3 & 79.8 \\
\hline $\mathrm{P}$ & 96.9 & 99.8 & 103.5 & 99.6 & 104.7 & 106.4 & 94.8 \\
\hline $\mathrm{Pb}$ & 116.3 & 90.6 & 97.8 & 90.6 & 100.4 & 90.3 & 71.7 \\
\hline $\mathrm{Sb}$ & 92.4 & 102.0 & 81.2 & 95.7 & 98.2 & 105.3 & 83.3 \\
\hline $\mathrm{Si}$ & 96.2 & 98.8 & 113.9 & 101.7 & 92.6 & 105.5 & 92.5 \\
\hline Sn & 103.3 & 100.4 & 96.8 & - & 103.5 & 101.6 & - \\
\hline $\mathrm{Sr}$ & 90.4 & 99.9 & 107.9 & 94.2 & 100.3 & 101.7 & 88.9 \\
\hline $\mathrm{Ti}$ & 95.9 & 103.9 & 95.8 & 95.2 & 98.5 & 99.5 & 101.4 \\
\hline V & 101.9 & 102.3 & 101.1 & 91.5 & 97.3 & 123.6 & 99.1 \\
\hline W & 84.3 & 87.3 & 99.0 & 90.6 & 105.3 & 132.8 & 87.1 \\
\hline $\mathrm{Zn}$ & 97.5 & 98.6 & 97.5 & 91.1 & 96.6 & 97.7 & 102.2 \\
\hline LHV & 103.4 & 100.5 & 99.5 & 100.9 & 99.7 & 99.5 & 101.4 \\
\hline
\end{tabular}

usual way of sampling and analyzing waste or SRF. As the waste stream in this study has undergone some additional procedures, which are always accompanied by additional errors, the RSVs are expected to be lower when the waste is directly analyzed without additional screening or sorting steps. The conclusion of Part I, stating that the quality of the sampling can only be rated in relation to the analytical target, also applies to chemical analyses. The developed regression models show a first attempt to predict element concentrations based on data from sorting analyses. While the majority of the results for most elements showed good accuracy $( \pm 20 \%$ of the original value), several aspects need to be further investigated. Firstly, the fact that the data come from one replication experiment and show high heterogeneity in material composition and element content concludes that several calibration datasets for different waste streams or waste streams with different origins must be available for a significant analysis of unknown datasets. This procedure is complex and time-consuming but must be considered if the need for a real-time method for chemical analysis should be continued. Nevertheless, the available data and the results from the regression models can be used to investigate and evaluate a model for a digital sampling procedure and interpret the effects of a varying number of samples, sample mass, and the time interval between sampling.

Supplementary Information The online version contains supplementary material available at https://doi.org/10.1007/s13762-021-03567-w.

Acknowledgements Partial funding for this work was provided by The Center of Competence for Recycling and Recovery of Waste 4.0 (acronym ReWaste4.0) (contract number 860 884) under the scope of the COMET - Competence Centers for Excellent Technologies - financially supported by BMK, BMDW, and the federal states of Styria, managed by the FFG. 
Authors' contributions Not applicable.

Funding Open access funding provided by Montanuniversität Leoben.

Availability of data and material (data transparency) Data are part of the supporting material of this manuscript as well as another manuscript (Viczek et al. in submission b) that is under consideration for publication in a peer-reviewed journal focusing on different aspects of the investigations.

Code availability Software application or custom code: not applicable.

\section{Declarations}

Conflict of interest The authors declare no conflict of interest.

Open Access This article is licensed under a Creative Commons Attribution 4.0 International License, which permits use, sharing, adaptation, distribution and reproduction in any medium or format, as long as you give appropriate credit to the original author(s) and the source, provide a link to the Creative Commons licence, and indicate if changes were made. The images or other third party material in this article are included in the article's Creative Commons licence, unless indicated otherwise in a credit line to the material. If material is not included in the article's Creative Commons licence and your intended use is not permitted by statutory regulation or exceeds the permitted use, you will need to obtain permission directly from the copyright holder. To view a copy of this licence, visit http://creativecommons.org/licenses/by/4.0/.

\section{References}

Amlinger F, Pollak M, Favoino E (2004) Heavy metals and organic compounds from wastes used as organic fertilizers: Annex 2 - Compost quality definition-legislation and standards. https://ec.europa. eu/environment/waste/compost/pdf/hm_annex2.pdf. Accessed 28 November 2019

Andersen JK, Boldrin A, Christensen TH, Scheutz C (2010) Mass balances and life-cycle inventory for a garden waste windrow composting plant (Aarhus, Denmark). Waste Manag Res 28:1010-1020. https://doi.org/10.1177/0734242X09360216

ASI (Austrian Standards Institute) (2002) ÖNORM EN 13656 Characterization of waste-Microwave assisted digestion with hydrofluoric $(\mathrm{HF})$, nitric $(\mathrm{HNO} 3)$ and hydrochloric $(\mathrm{HCl})$ acid mixture for subsequent determination of elements. Issued on 01/12/2002

ASI (Austrian Standards Institute) (2007) ÖNORM EN 14346 Characterization of waste-Calculation of dry matter by determination of dry residue or water content. Issued on 01/03/2007

ASI (Austrian Standards Institute) (2011a) ÖNORM EN 15411 Solid recovered fuels - Methods for the determination of the content of trace elements (As, Ba, Be, Cd, Co, Cr, $\mathrm{Cu}, \mathrm{Hg}, \mathrm{Mo}, \mathrm{Mn}, \mathrm{Ni}, \mathrm{Pb}$, $\mathrm{Sb}, \mathrm{Se}, \mathrm{Tl}, \mathrm{V}$ and $\mathrm{Zn}$ ). Issued on 15/10/2011

ASI (Austrian Standards Institute) (2011b) ÖNORM EN 15413 Solid recovered fuels-Methods for the preparation of the test sample from the laboratory sample. Issued on 15/10/2011

ASI (Austrian Standards Institute) (2011c) ÖNORM EN 15443 Solid recovered fuels-Methods for the preparation of the laboratory sample. Issued on 15/10/2011

ASI (Austrian Standards Institute) (2011d) ÖNORM EN 15359 Solid recovered fuels-Specifications and classes. Issued on 15/12/2011
ASI (Austrian Standards Institute) (2016) ÖNORM EN 14582 Characterization of waste-Halogen and sulfur content-Oxygen combustion in closed systems and determination methods

ASI (Austrian Standards Institute) (2017) ÖNORM EN ISO 17294-2 Water quality-Application of inductively coupled plasma mass spectrometry (ICP-MS)—Part 2: Determination of selected elements including uranium isotopes

Astrup T, Riber C, Pedersen AJ (2011) Incinerator performance: effects of changes in waste input and furnace operation on air emissions and residues. Waste Manag Res 29:57-68. https://doi.org/10.1177/ $0734242 X 11419893$

Beilicke G, Wesenigk H (1987) Zusammenstellung von Heizwerten für die Brandlastberechnung

BMLFUW (Bundesministerium für Land- und Forstwirtschaft, Umwelt und Wasserwirtschaft) (2010) Verordnung über die Verbrennung von Abfällen (Abfallverbrennungsverordnung-AVV)

Brunner PH, Rechberger H (2015) Waste to energy - key element for sustainable waste management. Waste Manag 37:3-12. https://doi. org/10.1016/j.wasman.2014.02.003

Cohen J (1988) Statistical power analysis for the behavioral sciences, 2nd edn. Taylor and Francis, Hoboken

DIN (Deutsches Institut für Normung) (2000) DIN 51900-1 Testing of solid and liquid fuels - Determination of gross calorific value by the bomb calorimeter and calculation of net calorific value-part 1: Principles, apparatus, methods. Deutsches Institut für Normung (DIN)

DIN (Deutsches Institut für Normung) (2009) DIN EN ISO 10304-1 Water quality-Determination of dissolved anions by liquid chromatography of ions-Part 1: Determination of bromide, chloride, fluoride, nitrate, nitrite, phosphate and sulfate. Deutsches Institut für Normung (DIN)

DIN (German Institute for Standardization) (1997) DIN 51719 Testing of solid fuels-Solid mineral fuels-Determination of ash content. Issued 07/1997. German Institute for Standardization (DIN)

DS (Danish Standards) (2013) DS 3077 Representative sampling - horizontal standard 03.120.30; 13.080 .05

EC (European Commission) (2008a) Directive 2008/98/EC of the European Parliament and of the Council of 19 November 2008 on waste and repealing certain directives (waste framework directive)

EC (European Commission) (2008b) Regulation (EC) No 1272/2008 of the European Parliament and the Council of December 162008 on classification, labelling and packaging of substances and mixtures

EC (European Commission) (2010) Directive 2010/75/EU of the European Parliament and of the Council of 24 November 2010 on industrial emissions (integrated pollution prevention and control)

EC (European Commission) (2011) Commission Regulation (EU) No 494/2011 of 20 May 2011 amending Regulation (EC) No 1907/2006 of the European Parliament and of the Council on the Registration, Evaluation, Authorisation and Restriction of Chemicals (REACH) as regards Annex XVII (Cadmium)

Ellison SLR, Williams A (2012) EURACHEM/CITAC Guide CG 4 Quantifying Uncertainty in Analytical Measurement. QUAM:2012. P1, 3rd edition. https://www.eurachem.org/images/stories/Guides/ pdf/QUAM2012_P1.pdf

Esbensen KH, Julius LP (2009) Representative sampling, data quality, validation-a necessary trinity in chemometrics. In: Tauler R, Walczak B, Brown SD (eds) Comprehensive chemometrics: chemical and biochemical data analysis. Elsevier, Burlington, pp 1-20

Esbensen KH, Wagner C (2014) Theory of sampling (TOS) versus measurement uncertainty (MU) - a call for integration. TrAC Trends Anal Chem 57:93-106. https://doi.org/10.1016/j.trac.2014.02.007

Esbensen KH, Swarbrick B, Westad F, Whitcombe P, Andersen M (2018) Multivariate Data Analysis: An introduction to Multivariate Analysis, Process Analytical Technology and Quality by Design, 6th Edition, CAMO Software AS Oslo \& Magnolia TX 
Flamme S, Gallenkemper B (2001) Inhaltsstoffe von Sekundärbrennstoffen, Ableitung der Qualitätssicherung der Bundesgütegemeinschaft Sekundärbrennstoffe e. V. Muell und Abfall:699-704

Flamme S, Geiping J (2012) Quality standards and requirements for solid recovered fuels: a review. Waste Manag Res 30:335-353. https:// doi.org/10.1177/0734242X12440481

Götze R, Boldrin A, Scheutz C, Astrup TF (2016) Physico-chemical characterisation of material fractions in household waste: overview of data in literature. Waste Manag 49:3-14. https://doi.org/ 10.1016/j.wasman.2016.01.008

Greenacre MJ (2019) Compositional data analysis in practice. Chapman \& Hall/CRC Interdisciplinary statistics series

Gy PM (1995) Introduction to the theory of sampling I. Heterogeneity of a population of uncorrelated units. TrAC Trends Anal Chem 14:67-76. https://doi.org/10.1016/0165-9936(95)91474-7

Gy P (1998) Sampling for analytical purposes. John Wiley \& Sons, Hoboken

Gy P (2004) Sampling of discrete materials - a new introduction to the theory of sampling. Chemom Intell Lab Syst 74:7-24. https://doi. org/10.1016/j.chemolab.2004.05.012

Holleman AF, Wiberg E, Wiberg N (2007) Lehrbuch der anorganischen Chemie, 102., stark umgearb. u. verb. Aufl. de Gruyter, Berlin

Kandlbauer L, Khodier K, Ninevski D, Sarc R (2020) Sensor-based particle size determination of shredded mixed commercial waste based on two-dimensional images. Waste Manag. https://doi.org/ 10.1016/j.wasman.2020.11.003

Khodier K, Viczek SA, Curtis A, Aldrian A, O'Leary P, Lehner M, Sarc R (2020) Sampling and analysis of coarsely shredded mixed commercial waste. Part I: procedure, particle size and sorting analysis. Int J Environ Sci Technol 17:959-972. https://doi.org/10.1007/ s13762-019-02526-w

Kjeldsen P, Barlaz MA, Rooker AP, Baun A, Ledin A, Christensen TH (2002) Present and long-term composition of msw landfill leachate: a review. Crit Rev Environ Sci Technol 32:297-336. https://doi.org/ 10.1080/10643380290813462

Krämer P (2017) Entwicklung von Berechnungsmodellen zur Ermittlung relevanter Einflussgrößen auf die Genauigkeit von Systemen zur nahinfrarotgestützten Echtzeitanalytik von Ersatzbrennstoffen, 1. Auflage. Schriftenreihe zur Aufbereitung und Veredlung, vol 66. Shaker, Aachen, Aachen

Krämer P, Flamme S, Schubert S, Gehrmann H, Glorius T (2016) Entwicklungen zur Echtzeitanalytik von Ersatzbrennstoffen. In: Thomé-Kozmiensky KJ (ed) Energie aus Abfall. TK Verlag Karl Thomé-Kozmiensky, Neuruppin

Lorber KE, Sarc R, Aldrian A (2012) Design and quality assurance for solid recovered fuel. Waste Manag Res 30:370-380. https://doi.org/ 10.1177/0734242X12440484

Massart DL, Vandeginste BGM, Buydens LMC, de Jong S, Lewi PJ, Smeyers-Verbeke J (1997) Handbook of chemometrics and qualimetrics: Part A. Data handling in science and technology. Elsevier, Amsterdam

MathWorks (2020a) isoutlier. https://de.mathworks.com/help/matlab/ref/ isoutlier.html. Accessed 3 December 2020

MathWorks (2020b) kstest. https://de.mathworks.com/help/stats/kstest. html. Accessed 3 December 2020

MathWorks (2020c) plsregress. https://de.mathworks.com/help/stats/ plsregress.html. Accessed 3 December 2020

Morf LS, Brunner PH, Spaun S (2000) Effect of operating conditions and input variations on the partitioning of metals in a municipal solid waste incinerator. Waste Manag Res 18:4-15. https://doi.org/ 10.1034/j.1399-3070.2000.00085.x

Pivnenko K, Granby K, Eriksson E, Astrup TF (2017) Recycling of plastic waste: screening for brominated flame retardants (BFRs). Waste Manag 69:101-109. https://doi.org/10.1016/j.wasman.2017.08.038

Pomberger R, Aldrian A, Sarc R (2015) Grenzwerte - Technische Sicht zur rechtlichen Notwendigkeit. In: Piska C, Lindner B (eds)
Abfallwirtschaftsrecht Jahrbuch 2015. NWV Neuer wissenschaftlicher Verlag, Wien, Graz, pp 269-289

Ramsey MH, Ellsion SLR, Rostron P (2019) Eurachem/EUROLAB/ CITAC/Nordtest/AMC Guide: Measurement uncertainty arising from sampling: a guide to methods and approaches. Second Edition: A guide to methods and approaches

Sarc R, Seidler IM, Kandlbauer L, Lorber KE, Pomberger R (2019) Design, quality and quality assurance of solid recovered fuels for the substitution of fossil feedstock in the cement industry - Update 2019. Waste Manag Res 37:885-897. https://doi.org/10.1177/07342 $42 X 19862600$

Slijkhuis C (2018) Recycling von Kunststoffen aus EAG bei gleichzeitiger Eliminierung von Schadstoffen. In: Pomberger R, Adam J, Aldrian A, Curtis A, Friedrich K, Kranzinger L, Küppers B, Lorber KE, Möllnitz S, Neuhold S, Nigl T, Pfandl K, Rutrecht B, Sarc R, Sattler T, Schwarz T, Sedlazeck P, Viczek SA, Vollprecht D, Weißenbach T, Wellacher M (eds) Vorträge-Konferenzband zur 14. Recy \& DepoTech-Konferenz, pp 261-264

Smith SR (2009) A critical review of the bioavailability and impacts of heavy metals in municipal solid waste composts compared to sewage sludge. Environ Int 35:142-156. https://doi.org/10.1016/j. envint.2008.06.009

Turner A (2019) Cadmium pigments in consumer products and their health risks. Sci Total Environ 657:1409-1418. https://doi.org/10. 1016/j.scitotenv.2018.12.096

Turner A, Filella M (2017) Field-portable-XRF reveals the ubiquity of antimony in plastic consumer products. Sci Total Environ 584585:982-989. https://doi.org/10.1016/j.scitotenv.2017.01.149

Vandeginste BGM, Massart DL, Buydens LMC, de Jong S, Lewi PJ, Smeyers-Verbeke J (1998) Multivariate calibration. In: Vandeginste BGM (ed) Handbook of chemometrics and qualimetrics: Part B. Elsevier, Amsterdam

Viczek SA, Aldrian A, Pomberger R, Sarc R (2020) Origins and carriers of $\mathrm{Sb}, \mathrm{As}, \mathrm{Cd}, \mathrm{Cl}, \mathrm{Cr} \mathrm{Co}, \mathrm{Pb}, \mathrm{Hg}$, and $\mathrm{Ni}$ in mixed solid wasteliterature-based evaluation. Waste Manag 103:87-112. https://doi. org/10.1016/j.wasman.2019.12.009

Viczek SA, Lorber KE, Sarc R (2021a) Production of contaminantdepleted solid recovered fuel from mixed commercial waste for co-processing in the cement industry. Fuel 294:120414. https://doi. org/10.1016/j.fuel.2021.120414

Viczek SA, Khodier K, Kandlbauer L, Aldrian A, Redhammer G, Tippelt G, Sarc R (2021b) The particle size-dependent distribution of chemical elements in mixed commercial waste and implications for enhancing SRF quality. Sci Total Environ 776:145343. https://doi. org/10.1016/j.scitotenv.2021.145343

Viczek SA, Aldrian A, Pomberger R, Sarc R (2021c) Origins of major and minor ash constituents of solid recovered fuel for co-processing in the cement industry. Waste Manag 126:423-432. https://doi.org/ 10.1016/j.wasman.2021.03.032

Vrancken C, Longhurst PJ, Wagland ST (2017) Critical review of realtime methods for solid waste characterisation: informing material recovery and fuel production. Waste Manag 61:40-57. https://doi. org/10.1016/j.wasman.2017.01.019

Wagner C, Esbensen KH (2012) A critical review of sampling standards for solid biofuels - missing contributions from the Theory of Sampling (TOS). Renew Sustain Energy Rev 16:504-517. https://doi. org/10.1016/j.rser.2011.08.016

Wagner C, Esbensen KH (2015) Theory of sampling: four critical success factors before analysis. J AOAC Int 98:275-281. https://doi. org/10.5740/jaoacint.14-236

Weissenbach T, Sarc R (2021) Investigation of particle-specific characteristics of non-hazardous, fine shredded mixed waste. Waste Manag:162-171. https://doi.org/10.1016/j.wasman.2020.09.033 